\title{
Study on Academic Atmosphere Construction in College from Perspective of Teaching Quality
}

\author{
Hongna Guo 1,2 \\ School of management, Tianjin University of Technology, \\ Tianjin, 300384, China ghn_999@163.com \\ 2Security Department, Luoyang Normal University \\ Luoyang Henan, 471022, China
}

\begin{abstract}
Construction of academic atmosphere is a very important part of university personnel trailing, which is one of the important internal factors affecting universities to improve the quality of education and teaching. It is an eternal theme of college education teaching and the essential guarantee of college's sustainable development. The 12th Five-year Plan proposed the idea about improving education quality. By analyzing one hundred and thirty-six students' academic records of the automation of a university from freshman to junior, the author tries to use the method of multiple regression analysis to analyze the data from freshman to junior to point out the key factors which affect academic atmosphere construction, to further improve and strengthen academic atmosphere construction and to provide valuable basis and effective way from the perspective of teaching quality management.
\end{abstract}

Keywords- undergraduate; teaching quality; study status; data statistics; multiple regression modle

\section{INTRODUCTION}

At the present era, competition in the world can finally be deduced to the competition of the talents, especially innovative and applied talents. The $12^{\text {th }}$ Five-year Plan proposed the idea about improving education quality. A good academic atmosphere is an important standard to measure high or low of an university's teaching quality, the strength and effect of academic atmosphere construction directly influence on universities' teaching quality. So, the research of academic atmosphere based on teaching quality is especially important.

\section{A. The meaning of academic atmosphere}

Academic atmosphere' is widely used in educational circles. The explanation of academic atmosphere is "the atmosphere of the school, academic or general learning in 'Modern Chinese dictionary'. There have not been reached a consensus about the definition of academic atmosphere in many research results of academic atmosphere. The main points are as follows: Huang Daren thinks that 'academic atmosphere is broad concept, it is the atmosphere of doing scholarly research, reading and conducting oneself' [1,2]; Zheng Jiamao believes that 'academic atmosphere is the integrated performance of learning objective, learning attitude and behaviour'[3]; Han Yanming considers that 'academic atmosphere refers to behavioral pattern that learners accept education consciously and promote the full development of body and mind'[4]; Xue Hao believes that 'academic atmosphere is a stable kind of the purpose of the scholarship, the scholarly spirit, the attitude toward research and scholarship methods. It is developed in a long-term education practice by all the teachers and the students of universities.[5].

This paper regards academic atmosphere as learning styles of students, which includes many components, such as learning objective, learning attitude, learning ability, learning quality, learning behavior and mental condition, mental outlook, which constitute a organic system. And it is a common psychological tendency and behavior trend that is formed in the learning process and it is also a stable behavior habits formed by the long-term integration and condensation [6].

\section{B. The main problems of academic atmosphere construction}

At present, the mainstream of academic atmosphere is good in Chinese universities. Students are working hard and seriously, but there are still some problems that cannot be neglected.

1) Unclear Learning objective, not the straight study manner. Some students are influenced by the view of the uselessness of study and have no clear learning goals. They believe that the purpose of going to the college is to get a diploma. Although some students have clear study goals, with strong utilitarianis m, they link acade mic records with a comfortable and well-paid job. Other students are at a loss in the study, they are completely made to deal with study in order to pass the exam [7].

2) Unstable Professional thought. Because of the influence of many negative factors in the community, many students cannot exactly recognize and deal with their majors after they enter colleges. They excessively emphase on self-awareness and personal hobits, finally, the academic achievement is not ideal, even cannot pass the exam.

3) Poor self-discipline ability. Undergraduates will release their physical and mental stress after graduating from high schools and entering the rich and colorful university campus. Facing the new environment and learning mode, some students show blundering mood and learning energy scattered; some students are addicted to the Internet; some students are spending all teh time 
staying with their boyfriends or girlfriends; some students are often late for school, truancy, and don't listen carefully in class, which seriously influence and damage academic atmosphere construction of colleges and universities.

\section{The focal point of academic atmosphere construction work}

The academic atmosphere construction is a complex and systematic work, which is directly or indirectly affected by every jobs of universities. Based on teaching quality, this paper is discussing how to improve academic atmosphere. The teaching quality mainly depends on teachers' teaching quality, students' learning quality and education management. Depending on the analysis of academic records, it gets the factors which are relative to academic atmosphere construction. The paper elucidates which problems are needed to be solved with analyzing those relative factors from those three aspects of teaching quality management.

\section{THE EMPIRICAL ANALYSISOF ACADEMIC RECORDS AND ACADEMIC ATMOSPHERE CONST RUCTION}

\section{A. The sources of data}

The data comes from the academic records of 136 students from automation professional in 07 grade of a university. The used rules of data are as follows: For dropouts, the academic records that are not exist will be replaced by zero; for relegation students, the academic records will be replaced by the next year's results. Based on the view of justice, the paper uses the results of students as data processing and analyzes in the first exam.

B. Multiple regression analysis

1) Establish regression model

$$
\left\{\begin{array}{l}
Y=X \beta+\varepsilon \\
\varepsilon \sim N(0, \Sigma)
\end{array}\right.
$$

$Y=\left(\begin{array}{llll}y_{21} & y_{22} & \cdots & y_{2 n} \\ y_{31} & y_{32} & \cdots & y_{3 n}\end{array}\right)^{T} y_{i j}$ means that the $j^{t h}$ student's average scores at the $i^{\text {th }}$ school year $i=2,3 \cdot j=1,2, \ldots, n \cdot X=\left(1, x_{j l}\right)_{n \times(p+1)}$, $x_{j l}(j=1,2, \ldots, n . l=1,2, \ldots, p)$ means that the $j^{\text {th }}$ student's scores of the $l^{\text {th }}$ course, $\beta=\left(\begin{array}{llll}\beta_{20} & \beta_{21} & \cdots & \beta_{2 p} \\ \beta_{30} & \beta_{31} & \cdots & \beta_{3 p}\end{array}\right)_{(p+1) \times 2}^{T} \quad \beta \quad r$ means estimated parameters.

$l=11, n=136$. The courses of the first term are as follows. ${ }^{x_{1}}$ means College English I, ${ }^{x_{2}}$ means Higher mathematics AI, ${ }^{x_{3}}$ means Engineering drawing with AUTOCAD, ${ }^{x_{4}}$ means Computer Culture Basis, ${ }^{x_{5}}$ means
Military Theory, ${ }^{x_{6}}$ means Moral Cultivation and Legal Basis;

The courses of the second term are as follows. $x_{7}$ means C Language Program Design, ${ }^{x_{8}}$ means College Physics AI, ${ }^{x_{9}}$ means College Physics Experiment AI, $x_{10}$ means College English II, $x_{11}$ means Higher Mathematics AII 1.

Use MINITAB software to analysis the data of academic records, the estimation value of $\beta$ is as follows.

$\beta=\left(\begin{array}{cccccccc}17.57 & 0.1648 & -0.0022 & -0.0061 & 0.0060 & 0.0168 & -0.0099 & 0.1352 \\ 11.58 & 0.1649 & -0.0323 & 0.0397 & -0.0184 & -0.0270 & -0.0270 & 0.1149\end{array}\right.$ $\left.\begin{array}{llll}0.0800 & 0.1066 & 0.2055 & 0.0794\end{array}\right)^{T}$ $\begin{array}{llll}0.1363 & 0.1655 & 0.1967 & 0.0922\end{array}$

2) Test of significant. Regression equation significant examination shows that the regression equations are significantly related. It can be known from the regression coefficient significant test that $y_{2}$ is significantly influenced by $x_{1}$ (College English I), $x_{7}(\mathrm{C}$ Language Program Design) $x_{8}$ (College Physics AI), $x_{10}$ (College English II), $x_{11}$ (Higher Mathematics AII). $y_{3}$ is significantly influenced by $x_{1}$ (College English I), $x_{8}$ (College Physics AI), $x_{10}$ (College English II), $x_{11}$ (Higher Mathematics AII).

3) Stepwise regression analysis. The author finds that the significant correlation exists between students' grades from the above analysis. According to this phenomenon, the author tends to find out several courses of the first academic year significantly correlate later learning by using stepwise regression analys is (Backward method). The optimum regression equations are as follows:

$$
\begin{aligned}
& y_{2}=24.21+0.162 x_{1}+0.154 x_{7}+0.083 x_{8}+0.211 x_{10}+0.081 x_{11} \\
& y_{3}=5.665+0.188 x_{1}+0.152 x_{8}+0.216 x_{9}+0.228 x_{10}+0.102 x_{11}
\end{aligned}
$$

From the above analysis, it can be known that there is significant correlation between the first academic year and the later learning.

During the first academic year, there are three categories of courses that affect students' later learning. The first kind is College English I and College English II, which explains that the key of learning English lying in the foundation; the second kind is Higher Mathematics AII which reflects students' logical thinking ability and scientific literacy and reflects the acceptance ability of students. In addition, the third kind is a category of course as C Language Program Design, College Physics AI and College Physics Experiment AI which reflect that basic specialized knowledge is the foundation of the professional knowledge learning. 
Table 1 shows that: The standard deviation of College Physics Experiment AI is 6.165, which is less than 9 which indicates that there is not difficult for students to learn this course. However, the average of College Physics Experiment AI is 79.632, which is relatively s mall among the average value of all subjects which reflects the problems of students' learning attitude. So, college students should quickly adapt to the new environment and correct learning attitude.

Table 1 shows that: The standard deviations of Higher Mathematics AI and Higher Mathematics AII are 13.10 and 30.31 respectively, which are far greater than 9 which shows that there is certain difficulty for students to study them and also shows that the cause of Higher Mathematics AII problems is just that students have not learned Higher Mathematics AI. So, college students should get used to the new teaching method and adjust learning method.

T ABLE I. LEARNING ACHIEVEMENTS STATISTICS

\begin{tabular}{|c|c|c|c|c|}
\hline Course name & $\begin{array}{l}\text { Average } \\
\text { value }\end{array}$ & $\begin{array}{l}\text { Standard } \\
\text { deviation }\end{array}$ & $\begin{array}{l}\text { Minimum } \\
\text { value }\end{array}$ & $\begin{array}{c}\text { Maximu } \\
\mathrm{m} \\
\text { value } \\
\end{array}$ \\
\hline College English I & 80.191 & 7.370 & 50 & 94 \\
\hline Higher Mathematics AI & 83.72 & 13.10 & 21 & 100 \\
\hline $\begin{array}{c}\text { Engineering Drawing with } \\
\text { AUTOCAD }\end{array}$ & 85.88 & 12.43 & 36 & 100 \\
\hline Computer culture basis & 83.426 & 8.213 & 51 & 97 \\
\hline Military theory & 76.794 & 6.288 & 57 & 90 \\
\hline $\begin{array}{l}\text { Moral cultivation and legal } \\
\text { basis }\end{array}$ & 82.912 & 4.461 & 73 & 93 \\
\hline $\mathrm{C}$ language program design & 82.375 & 11.553 & 49 & 100 \\
\hline College physics AI & 78.68 & 12.49 & 41 & 100 \\
\hline $\begin{array}{c}\text { College physics experiment } \\
\text { AI }\end{array}$ & 79.632 & 6.165 & 53 & 93 \\
\hline College English II & 74.846 & 7.867 & 50 & 90 \\
\hline Higher Mathematics AII & 81.51 & 20.31 & 0 & 100 \\
\hline
\end{tabular}

\section{The SUGGESTION AND COUNTER MEASURE OF} STRENGT HENING ACADEMIC ATMOSPHERE CONSTRUCTION SELECTING A TEMPLATE

\section{A. Strengthen the education of students' specialty}

The stability of the specialty thought directly influences students' interests of learning professional knowledge. The general phenomenon, such as unstable specialty thought, school-weary, escaping school, does not only exist in freshmen but also in junior and senior. The reason is that students don't know enough about their majors and are lack confidence of learning. In this case, universities can take the following measures to strengthen the education of students' specialty thoughts:

For the freshmen, colleges should organize professional academic lectures, which mainly introduces the development frontier and development direction of the majors. For the sophomore and junior, colleges can carry out short courses about four to eight class hours. Universities can invite famous scholars, expertise professors and enterprise technical personnel to give lecture to students. For the senior, employment guidance group can carry on employ ment guidance seminar for the students who will be applied for a job and are looking a job. The main contents of employment guidance seminar are to tell students about interview skills, professional knowledge being asked possibly in the interview and solve problems which students encountered in the interview.

\section{B. Perfecting teacher evaluation system}

At present, in Chinese universities, the research papers are deemed as the main factor in the teacher evaluation system. The evaluation system of teachers leads more and more teachers to put more attention on research papers being published. So the energy and the time on teaching study are gradually reduced. The mechanis m does not only depend on teachers' teaching initiative, but is also conductive to the improvement of teaching quality. So, universities can draw the following aspects into the teacher evaluation system.

1) The style of teacher. Ye Shengtao is the prominent educator in our country, who once pointed out: "the teachers' charm can produce a speechless and lasting effect, largely, it also decides the effect of the academic instruction." Teachers bear a grave responsibility of spreading the truth, teaching school and solving knotty problems. In the process of teaching, the teachers do not only impart knowledge, but also produce a subtle influence on the students think and their concept of morality. So, the style of teachers should be attached to the teacher evaluation system.

2) Students' evaluation of teaching. The students' evaluation of teaching is a kind of effective method for college teachers to reform the teaching quality. Its principal aspects include curriculum function, teaching effect, teaching style, teachers' performance and students' suggestion [8]. The orders of evaluation include unacceptable, acceptable, content, very good and excellent.

3) Teachers assess students. Teachers should always be as sessed their students' grasp of what they're being taught, Christensen contends. Knowing and controlling the level of influence of various factors will play an important guiding role for teachers to give effective learning guidance. So, it is very important for teachers to assess their students. The principal aspects of the teachers assess students are understanding what students want to learn, students' psychological condition, students' grades and individual differences. The orders of evaluation include incomprehension, knowing a little bit, comprehension and depth knowledge.

\section{Playing a role model of class monitors}

The class monitors are the foregoers of academic atmosphere construction. Their learning attitude, innovation ability, moral, self-managed and self-restrict ability affect all other students. Therefore, the class monitors can organize the study discussion group [9], and take them as an important form. By this way, students can improve learning effect and enhance the ability of self- 
study. The main content of the study discussion group are as following:

Knowing clearly the learning objectives, making selfstudy plan and group activities plan, etc.;

According to the teaching process and the teaching content, developing topic discussion and answering difficult problems in due time, etc.;

The numbers of the study group discuss the difficulties which are met in learning process and exchange learning methods and experiences;

Team members discuss teacher's teaching contents, teaching methods, and give feedback to the teachers about the needs of the most students on teaching content and changing teaching methods;

The class monitors should take the lead to participate in all kinds of activities held by school and regularly organize students to develop knowledge debates, community assistanting activities in order to enrich students' extracurricular life.

\section{CONCLUSION}

Academic atmosphere construction is a key part of universities teaching job, which is the foundation of improving the quality of education and teaching. Firstly, under the background of fierce international competition and domestic, clear the necessity of studying academic atmosphere construction based on teaching quality. Secondly, point out the key factors which affect academic atmosphere construction through analyzing academic records. Thirdly, the suggestion and countermeasure of improving academic atmosphere construction are put forward from three perspectives: education management, the teacher and the student.

Academic atmosphere construction is the eternal theme[10]. It is still needed to further explore and research how to fundamentally establish a perfect long-term mechanism. It requires schools, teachers, students and parents to work hard together, as well as the focus of the society. Only in this way can it be possible to set up a good style of studying and to promote the constantly improved of teaching quality.

\section{REFERENCES}

[1] Lai shao cong,"Establish teaching quality and enhance the quality of undergraduate education" China University Teaching, 10,56- 61,2014.

[2] Huang Daren, "talking about university's academic atmosphere", journal of nat ional academy of education administrational, 2, 34-39, 2003.

[3] Zheng Jiamao, "on improving attitude of study of undergraduate", Research on education Tsinghua,4,40-42, 2004.

[4] Han Yanming, "on construction of the academic atmosphere: an eternal theme of academic sustainable development", journal of higher education, 3,19-24,2006.

[5] Xue Hao, "To strengthen construction of the university academic atmosphere", China adult education, 12,44-45, 2006.

[6] Liu Lijun, "study on academic atmosphere construction in ordinary technical undergraduate course college from perspective of education management", Tianjin university, 2009.

[7] Zhang Zhenping, "on the construction of the academic atmosphere"china higher education research,7, 77-78,2005.

[8] Ye Xinzhi," Research on the teaching blind spots in Chinese universities from the perspective of teaching characteristics in American Universities", journal of higher education, 11, 68$74,2011$.

[9] Huang Yi ping,"The exemplary vanguard: the role location of university students party members in the academic atmosphere construction", journal of JiangXi youth vocat ional college, 3, 61-62, 2014.

[10] Pan xiao ming "Recognition of the teaching quality and teaching evidence"Contemporary Educational Science,3,16-20,2015. 